\title{
TEKNIK PENGULURAN OTOT-OTOT LEHER UNTUK MENINGKATKAN FUNGSIONAL LEHER PADA PENDERITA NYERI TENGKUK NON-SPESIFIK
}

\author{
Bambang Trisnowiyanto \\ Jurusan Fisioterapi Politeknik Kesehatan Kemenkes.R.I. Surakarta
}

\begin{abstract}
ABSTRAK
Nyeri tengkuk merupakan masalah yang umum dijumpai yaitu 3,5\% kasus per 1.000 orang. Kondisi ini dialami dua dari tiga orang selama masa hidupnya, nyeri tengkuk akan mengakibatkan terganggunya aktivitas fungsional sehari-hari. Tujuan penelitian ini ialah untuk mengetahui pengaruh pemberian teknik penguluran otot-otot leher terhadap peningkatan fungsional leher pada penderita nyeri tengkuk non spesifik. Rancangan penelitian yang digunakan ialah one group pre-test and post-test design. Subjek penelitian sebanyak 23 orang yang terdiri dari 10 orang laki-laki dan 13 orang perempuan dengan rentang usia lebih dari 20 tahun. Subjek dipilih dengan kriteria inklusi dan eksklusi. Subjek mendapat perlakuan berupa latihan penguluran sebanyak 6 kali seminggu atau setiap hari berturut-turut selama 1 minggu. Program latihan penguluran diberikan selama 20-30 menit setiap sesi latihan.Hasil uji analisis data dengan non parametrik Wilcoxon test, diperoleh $\mathrm{p}=0.000$ ( $\mathrm{p}<0.05$ ). Nilai kemampuan fungsional dengan neck pain and disability visual analogue scale (NPAD). Terdapat pengaruh latihan penguluran otot-otot leher terhadap peningkatan fungsional leher pada penderita nyeri tengkuk non spesifik.
\end{abstract}

Kata kunci : latihan penguluran, fungsional leher

\begin{abstract}
Neck pain is a common problem of $3.5 \%$ of cases per 1,000 people. This condition is experienced by two out of three people during life. Neck pain will result in disruption of daily functional activities. The purpose of this study is to determine the effect of the provision of stretching of the neck muscles to the functional improvement of the neck in patients with non specific nape pain.This research design is one group pre-test and post-test design. Research subjects were 23 people consisting of 10 men and 13 women with age range more than 20 years. Subject chosen by inclusion and exclusion criteria. The subject received treatment in the form of stretching exercises 6 times a week or every day for 1 week in a stretching exercise program is given for 20-30 minutes each training session. Results of data analysis test with non parametric Wilcoxon test, obtained $p=0.000(p<0.05)$. The value of functional ability with neck pain and disability visual analogue scale (NPAD).There is an effect of neck muscle stretching exercises on the functional improvement of the neck in patients with non specific nape pain.
\end{abstract}

Keyword: stretching exercises, functional neck

\section{PENDAHULUAN}

Nyeri tengkuk atau neck pain adalah nyeri yang dirasakan pada bagian belakang dari susunan tulang belakang yang paling atas atau cervical. Rasa nyeri yang dirasakan dapat menjalar hingga ke daerah kepala dan bahu bahkan jari-jari tangan. Nyeri tengkuk merupakan masalah yang umum dijumpai. Data internasional tahun 1996 menyebutkan 3,5\% kasus per 1.000 orang (Furman, 2009). Paling tidak dua dari tiga orang akan mengalaminya selama hidup (Thompson et $a l$, 2013). Penyebab potensial dari nyeri tengkuk adalah adanya tekanan pada jaringan lunak, tulang, atau sendi pada area servikal. Pada beberapa kasus dapat pula diakibatkan trauma hiperekstensi atau whisplash injury, overuse dengan menunduk terlalu lama saat bekerja (Hudaya, 2009). Gejala yang ditimbulkan akibat nyeri pada tengkuk adalah berupa ketegangan otot atau spasme di daerah leher yang mengakibatkan keterbatasan gerak leher sehingga fungsional leher akan terhambat. Penguluran otot atau stretching adalah salah satu cara untuk memberikan kelenturan pada otot sehingga mampu mengurangi retriksi atau ketegangan yang ditimbulkan akibat adanya rasa nyeri. Untuk memelihara daya tahan kerja dari otot maka penting untuk dilakukan latihan 
penguatan pada otot yang bersangkutan (Hurwitz et al, 2008).

\section{Latihan Penguluran (Stretching)}

Penguluran otot atau muscle stretching adalah teknik gerakan yang dilakukan untuk meregangkan otot beserta tendon, yang bertujuan untuk mengulur, melenturkan atau menambah fleksibilitas otot-otot yang dianggap bermasalah. Menurut Karlson (2011) bentuk-bentuk gerakan penguluran yang dapat dilakukan pada daerah leher adalah: (1) penguluran antefleksor leher, (2) penguluran ekstensor leher, (3) penguluran lateral fleksor leher, dan (4) penguluran rotator leher. Gerakan penguluran tersebut antara lain sebagai berikut:

1. Penguluran otot sternocleidomastoideus.

Subjek diposisikan duduk dengan kepala tegak kemudian lehernya digerakan rotasi ipsilateral dan extensi hingga maksimal dan posisi ini dipertahankan dan berikan dorongan untuk mengulur otot sternocleidomastoideus selama 8-10 hitungan atau dalam satuan detik kemudian dikembalikan pada posisi semula. Gerakan ini dilakukan juga pada sisi leher yang berlawanam yaitu kearah kiri dan kanan. Gerakan ini dilakukan sebanyak 4-8 kali pengulangan.
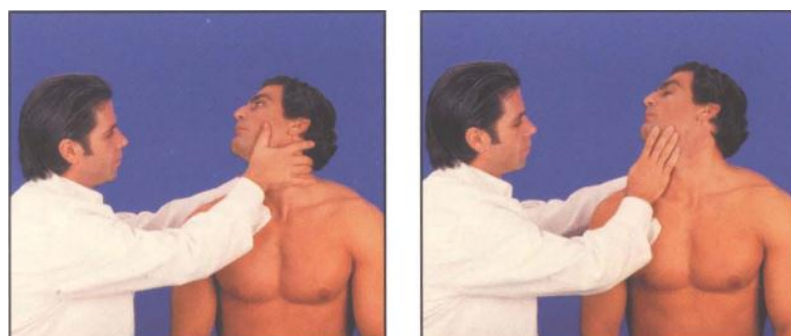

Gambar 1. Penguluran otot sternocleidomastoideus (kostopoulos, 2001)

\section{Penguluran otot scalenei}

Subjek diposisikan duduk dengan kepala tegak, kemudian leher diposisikan flexi kesamping dengan memberikan stabilisasi pada bahu dengan satu tangan dan satu tangan yang lain memegang sisi temporal kepala. Posisi ini dipertahankan dan berikan tekanan atau dorongan untuk mengulur otot scalenei selama 8-10 hitungan atau dalam satuan detik, kemudian dikembalikan pada posisi semula. Gerakan penguluran ini dilakukan juga pada sisi leher yang berlawanan, yaitu sisi kanan dan kiri. Gerakan ini dilakukan sebanyak 4-8 kali pengulangan.
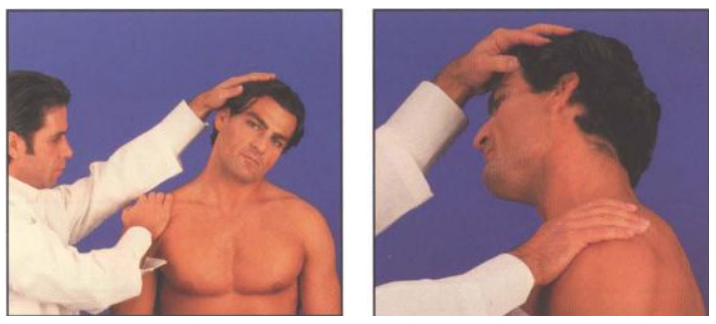

Gambar 2. Penguluran otot scalenei (kostopoulos, 2001)

3. Penguluran otot upper trapezius

Subjek diposisikan duduk tegak, kemudian kepala digerakan fleksi ke depan dan kesamping. Berikan stabilisasi pada bahu dan dorongan pada kepala bagian belakang agar terjadi elongasi pada otot upper trapezius. Pertahankan posisi ini selama 8-10 hitungan atau dalam satuan detik, kemudian kembalikan posisi kepala menjadi tegak kembali. Gerakan ini dilakukan juga pada sisi leher berlawanan yaitu sisi kiri dan kanan dengan setiap gerakan dilakukan sebanyak 4-8 kali pengulangan. 


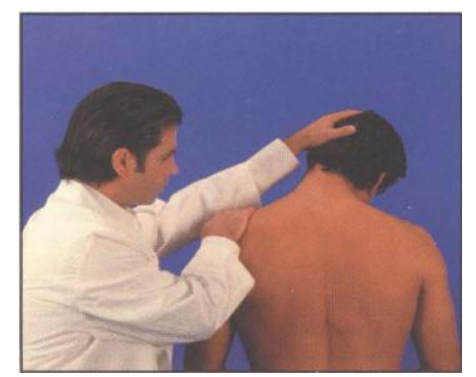

Gambar 3. Penguluran otot upper trapezius (kostopoulos, 2001)

4. Penguluran otot levator scapula

Subjek diposisikan duduk dengan kepala tegak. Kemudian kepala digerakan fleksi. lalu digerakan rotasi kontralateral, dan pertahankan posisi ini serta berikan dorongan atau elongasi pada otot levator scapula. Gerakan ini dilakukan juga pada kedua sisi leher dengan hitungan selama 810 detik.
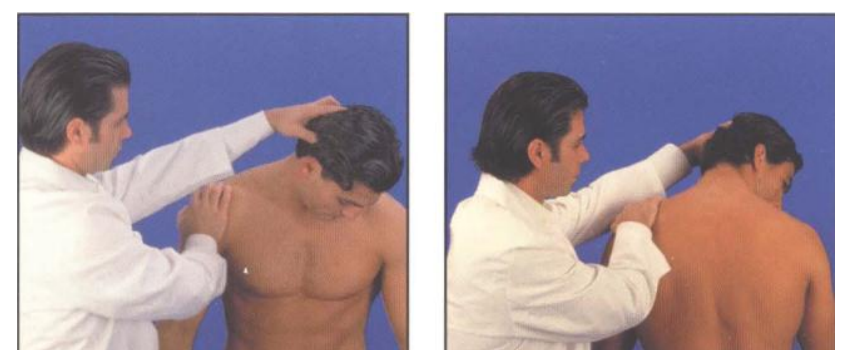

Gambar 4. Penguluran otot levator scapula (kostopoulos, 2001)

5. Penguluran otot splenius capitis

Subjek diposisikan tidur terlentang. Kemudian kepala diangkat ke depan dengan penyanggaan menggunakan 2 tangan pada kepala bagian belakang atau occipitalis. kepala ditekuk ke depan hingga dagu menyentuh dada atau sternum agar terjadi elongasi pada otot splenius capitis. Posisi ini dipertahankan 8-10 hitungan kemudian mengembalikan kepala pada posisi semula. Gerakan ini dilakukan sebanyak 4-8 kali pengulangan.

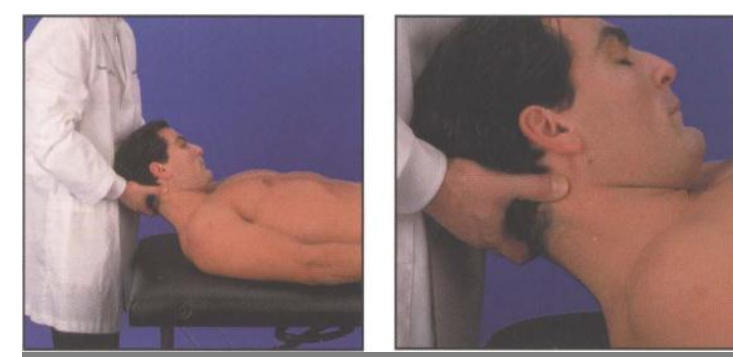

Gambar 3.Stretching otot splenius capitis (kostopoulos, 2001)

\section{Kemampuan Fungsional}

Kemampuan fungsional adalah kemampuan melakukan aktifitas kehidupan sehari-hari dengan tanpa bantuan orang lain atau mandiri. Kemampuan fungsional leher adalah kemampuan melakukan gerak leher yang melingkupi gerak menunduk, menoleh dan memutar kepala. Kemampuan fungsi leher sangat dipengaruhi oleh lingkup gerak sendi, fleksibilitas jaringan dan adanya nyeri. Kemampuan fungsional leher diukur dengan neck pain and disability visual analogue scale (NPAD).
Penelitian Viljanen (2003) tentang efek pemberian stretching dan dynamic exercise untuk mengaktifkan otot-otot pada regio leher dan bahu menyimpulkan bahwa stretching dan dynamic exercise efektif mengurangi nyeri pada leher. Penelitian Bertozzi et al (2013) tentang efek latihan dengan menggunakan stretching dan strenghtening dalam mengurangi nyeri dan disabilitas pada non spesific neck pain menyimpulkan bahwa latihan stretching dan strengthening efektif mengurangi nyeri jangka pendek dan menengah pada penderita non spesific neck pain. 


\section{METODE PENELITIAN}

Penelitian eksperimen kuasi dengan one group pretest and posttest design. Bertujuan untuk mengetahui pengaruh pemberian teknik penguluran otot-otot leher untuk peningkatan fungsional leher pada penderita nyeri tengkuk. Subjek yang digunakan adalah penderita nyeri tengkuk yang dipilih melalui kriteri inklusi: (1) sedang memiliki diagnosis fisioterapi nyeri pada otot-otot leher atau tengkuk atau myalgia daerah leher yang dibuktikan dengan indeks nyeri Neck Pain and Disability Analoge Scale (NPAD) (2) laki-laki maupun wanita dengan rentang usia 20-50 tahun (3) tidak menyandang disabilitas berupa deformitas pada cervical (5) bersedia mengikuti program latihan penguluran. Criteria eksklusinya: (1) memiliki nyeri tengkuk yang menjalar (cervical root syndrome), (2) memiliki diagnosis medis spondilosis cervicalis, osteoporosis dan post fraktur cervicalis, dan
(3) merasa pusing, mual bahkan muntah bila dilakukan tes ekstensi dan rotasi leher atau tes manuver arteri vertebro basiller. Subjek akan dilakukan drop out apabila: (1) lebih dari 2 kali secara berturut-turut tidak mengikuti program latihan penguluran, (2) subjek mengkonsumsi obat pereda nyeri saat mengikuti program intervensi. Program intervensi diberikan setiap pagi hari berturut-turut selama 6 hari dengan durasi 20-30 menit setiap sesi penguluran. Variabel penelitian ini adalah teknik latihan penguluran otot-otot leher dan kemampuan fungsional leher.

\section{HASIL ANALISIS DATA}

Karakteristik jenis kelamin subjek penelitian didominasi perempuan sebanyak 13 orang (56,5\%), dan laki-laki sebanyak 10 orang $(43,5 \%)$. Umur subjek lebih banyak pada kelompok umur 30-40 tahun.

Tabel 1. Karakteristik subjek

\begin{tabular}{|c|c|c|c|c|}
\hline \multirow{2}{*}{$\begin{array}{c}\text { Klasifikasi } \\
\text { umur }\end{array}$} & \multirow{2}{*}{ Laki - laki } & \multirow{2}{*}{ Perempuan } & \multirow{2}{*}{ Jumlah } & \multirow{2}{*}{$\%$} \\
\hline & & & & \\
\hline$<30$ tahun & 0 & 4 & 4 & 17,4 \\
\hline $30-40$ tahun & 7 & 6 & 13 & 56,5 \\
\hline$>40$ tahun & 3 & 3 & 6 & 26,1 \\
\hline Jumlah & 10 & 13 & 23 & 100 \\
\hline$\%$ & 43,5 & 56,5 & 100 & \\
\hline
\end{tabular}

Sumber : Data Primer

Kondisi fungsional leher subjek yang di ukur dengan Neck Pain and Disability Analoge Scale (NPAD) didapatkan rata-rata sebelum perlakuan sebesar 40,35 $\pm 19,639$ dan setelah perlakuan sebesar $26,30 \pm$ 13,583 .

Tabel 2. Nilai NPAD sebelum dan sesudah perlakuan

\begin{tabular}{lll}
\hline Nilai & Sebelum & Sesudah \\
\hline Nilai minimal & 7 & 5 \\
Nilai maksimal & 75 & 56 \\
Range & 68 & 51 \\
Rata - rata & 40,35 & 26,30 \\
Std. deviasi & 19,639 & 13,583 \\
\hline
\end{tabular}

Sumber : Data primer

Hasil uji beda dengan Wilcoxon latihan penguluran otot-otot leher terhadap didapatkan nilai $\mathrm{p}=0,000(\mathrm{p}<0,05)$ yang fungsional leher pada penderita nyeri menunjukkan bahwa terdapat pengaruh tengkuk.

Tabel 3. Uji beda Wilcoxon sebelum dan sesudah

\begin{tabular}{llll}
\hline Pre test & Post test & $P$ & Keterangan \\
\hline $40,35 \pm 19,639$ & $26,30 \pm 13,583$ & 0,000 & Ada pengaruh \\
\hline Sumber:
\end{tabular}

Sumber : Data Primer 


\section{PEMBAHASAN}

Perempuan mempunyai resiko lebih tinggi mengalami nyeri pada tengkuk. Hal ini sejalan dengan penelitian yang dilakukan Salo et al. (2009) tentang pengaruh latihan penguatan leher pada perempuan dengan nyeri leher kronis, terbanyak diderita oleh perempuan di rentang usia remaja hingga dewasa yakni 25-53 tahun dan paling banyak terjadi di pertengahan umur $30-40$ tahun.

Penguluran otot dapat menurunkan nyeri dan meningkatkan kemampuan fungsional leher pada penderita nyeri tengkuk. Prinsip penguluran otot atau peregangan dapat memperpanjang jaringan lunak dan mengalami pemendekan, dengan demikian dapat meningkatkan fleksibilitas gerak (Kisner, 2007). Subtansi P yang menumpuk pada otot akan menimbulkan rasa nyeri dan ketegangan pada otot. Tingginya tekanan intramuscular yang berhubungan dengan muscle tension dapat mengurangi sirkulasi pada otot yang dapat mengakibatkan peningkatan jaringan kolagen yang menyilang satu sama lain. Hal ini mengakibatkan adanya perlengketan aktin dan myosin. Dengan pemberian stretching maka respon otot ketika otot ditarik dan memanjang, kekuatan peregangan ditransmisikan ke serat otot melalui jaringan ikat (endomysium dan perimysium) yang menghubungkan interaksi molekul elemen noncontractile ke unit kontraktil otot dan sarkomer yang disusun oleh aktin dan myosin sehingga aktin dan myosin saling menjauh. Otot dapat terus memanjang dan aliran darah menjadi lancar. Dengan adanya perbaikan sirkulasi dan rileksasi otot-otot penggerak leher, maka akan berdampak pada penurunan nyeri yang dirasakan penderita (Kisner, 2007). Berkurangnya nyeri memberikan keberanian pada seseorang untuk menggerakkan leher saat melakukan aktivitas fungsional. Stretching atau penguluran dapat menurunkan nyeri melalui modulasi nyeri tingkat supraspinal (ekstra segmental) yaitu melibatkan sistem analgesik endogen yang dihasilkan oleh tubuh. Sistem analgesik endogen ini meliputi enkefalin, endorfin, serotonin dan adrenalin yang memiliki efek dapat menekan impuls nyeri.

Pelepasan sistem analgesik endogen oleh tubuh dipengaruhi oleh stimulasi serabut saraf A delta dan tipe $\mathrm{C}$ yang berjalan menuju transmission cell. Selanjutnya stimulus disalurkan ke reticular formation melalui spinoreticular tract. Dari spinoreticular tract stimulus diteruskan ke hypothalamus kemudian betta endorphin released yang menyebabkan nyeri berkurang. Setelah mereleased betta endorphin stimulus diteruskan menuju periqueductal grey dan dynorphin released. Selanjutnya stimulus diteruskan menuju raphe nucleus dan interneuron melalui dorso lateral tract yang mereleased serotonin dan enkephalin sehingga terjadi rileksasi pada otot leher (Budiman, 2005). Berkurangnya nyeri pada leher dapat meningkatkan rileksasi otot disekitar leher dan meningkatan kemampuan fungsional leher. Fleksibilitas merupakan kemampuan otot untuk memanjang atau mengulur semaksimal mungkin sehingga tubuh dapat bergerak dengan lingkup gerak sendi yang maksimal tanpa disertai dengan rasa nyeri. Dengan fleksibilitas yang baik maka tidak ada hambatan pada bagian tubuh dalam bergerak. Memelihara fleksibilitas otot juga sangat berperan dalam meningkatkan kekuatan otot leher untuk memperoleh ketahanan statis dan dinamis leher, memelihara luas gerak sendi dan kelenturan leher, serta memperoleh postur yang benar dan terkoreksinya muscle imbalance.

Penelitian ini sejalan dengan Hakkinen (2008) tentang perbedaan pengaruh pemberian strengthening dan stretching pada penderita neck pain, menunjukkan bahwa baik strengthening dan stretching maupun stretching saja sama-sama berpengaruh terhadap penurunan nyeri dan peningkatan kemampuan fungsional pasien, yang diukur dengan neck disability index.

\section{KESIMPULAN}

Terdapat pengaruh latihan penguluran otot-otot leher terhadap fungsional leher pada penderita nyeri tengkuk non spesifik.

\section{DAFTAR PUSTAKA}

Bethesda. (2009). Preventing Falls and Related Fractures. Diakses dari http://www.niams.nih.gov/Health_info , tanggal 23 Februari 2009.

Bertozzi L, Gardenghi I, Turoni F, capra F, Andrew A, Guccione, Pillastrini P, 2013; Effect of Therapeutic Exercise on Pain and Disability in the Management of Chronic Nonspecific Neck Pain: Systematic Review and 
Meta-Analysis of Randomized Trials, Phys Ther. 2013; 93:1026-1036.

Cailliet R, 1991; Neck and Arm Pain. Philadelphia; Edition 3, FA. Davis Company, United States of America, 96-123.

Fritz JM, Cleland JA, Childs JD, Whitman JM, Eberhart SL, 2007; Journal Development of a Clinical Prediction Rule for Guiding Treatment of a Subgroup of Patients With Neck Pain: Use of Thoracic spine Manipulation, Exercise, and Patient Education; Clinical Prediction Rule for Patients with Neck Pain; Vol 87, Number 1, Page 9-23.

Furman MB, 2009; Cervical Disk Disease; Diakses tanggal 3 maret 2011 dari http://emedicine.medscape.com/ arti cle/305720-overview

Glenn C, Terry MD, Thomas M, Chopp MD, 2000; Functional Anatomy of the Shoulder. J Athl Train. 2000 Jul-Sep; 35(3): 248-255

Häkkinen A, Salo P, Tarvainen U, Wiren K, Ylinen J, 2007; Effect of Manual Therapy an Stretching on Neck Muscle Strength and Mobility in Chronic Neck Pain, J Rehabilitation Medical, vol 39(7), hal. 575-579.

Hudaya P, 2009; Patofisiologi nyeri leher; Seminar nyeri leher 2009, Solo.

Hurwitz EL, Carrage EJ, van der Velde G, Caroll LJ, Nordin M, Guzman J, Peloso PM, Holm LWCote P, HoggJohnson S, Casidy JD, 2008; Treatment of neck pain: noninvasive interventions: results of the bone and joint decade 2000-2010 task force on neck pain and its associateddisorders. Spine.2008;15:S1 23S152.doi:10.1097/BRS.0b013e318 $1644 \mathrm{~b} 1 \mathrm{~d}$.

Karllson L Takala EP, Gerdle B, Larsson B, 2011; The effect of two different home-exercise programmes on

Widiastuti, 2005 ; Aspek Anatomi Terapan Pada Pemahaman Neuromuskulo skeletal Kepala Dan Leher Sebagai women suffering long-term neck muscle pain; European journal of pain supplements 2011; 5; 285

Kisner C Akbas E Atay AO Colby LA, 2007 Therapeutic exercise, Fifth Edition,. (Philadelpia : F.A)

Kustopoulos D, 2001; The Manual of Trigger Point and Myofascial Therapy; Edition $1^{\text {st }}$, Amazonstudent Co. , New York.

Parjoto, 2006; Terapi Listrik untuk Modulasi Nyeri, Ikatan Fisioterapi Indonesia cabang Semarang

Salo P, Häkkinen A, Kautiainen H, 2009; Effect of neck strength training on health-related quality of life in females with chronic neck pain: a randomized controlled 1-year followup study. Diakses tanggal 24 mei 2011 dari http://www.hqlo.com/ content $/ 8 / 1 / 48$

Samara D, 2007; Nyeri Musculoskeletal pada leher pekerja dengan posisi pekerjaan yang statis; Nyeri musculoskeletal pada pekerja, Universa

Thompson P, Morris D, Saynor M, 2013; Neck pain, Arthritis Research UK.

Tsakitzidis G, Remmen R, Dankaerts W, van Royen P, 2013; Non-Spesific Neck Pain an Evidence-Based Practice; European Scientific Jurnal, vol 9, hal 3.

Vernon H, Mior S, 1991; The Neck Disability Index :A Study of reliability and validity. $\mathbf{J}$ Manipulative Physiol Ther 14:409415,1991 Diakses April 2011 dari http://www. jmptonline. org/article/ S0161- 4754\% 2809\% 2900321-2

Viljanen M, Malmivaara A, Uitti J, 2013 ; Effectiveness of dynamic muscle training, relaxation training, or ordinary activity for chronic neck pain : randomised controlled trial. BMJ. 2003;327:475.

Landasan Penanganan Nyeri Kepala Tegang Primer. FK UNDIP Semarang 